\title{
RESEARCH
}

Open Access

\section{Endoscopic assisted microvascular decompression versus new antiepileptics and BOTOX in treatment of hemifacial spasm: a clinical trial}

Moamen Mohamed Morsy ${ }^{1 *}$ (D, Wael Ahmed Foaud ${ }^{2}$, Hisham Adel Abu-Elenain ${ }^{2}$ and Mohammed Abbas Aly ${ }^{2}$

\begin{abstract}
Introduction: Hemifacial spasm (HFS) is a chronic movement disorder characterized by twitching of muscles of facial expression which is innervated by the facial nerve. The condition is unilaterally, beginning in the orbicularis occuli, and later on progress to involve the perioral, platysma, and other muscles of facial expression. Endoscopic assisted microvascular decompression is considered the state of the art in hemi-facial spasm surgery. New antiepileptic have emerged with a new hope for good control with few side effects. Botulinum toxin is still a good option for some patients.
\end{abstract}

Methods: This study is a prospective study that was conducted on 30 patients with primary hemifacial spasm. Bilateral and secondary cases where excluded. All patients were subjected to proper pre-treatment assessment including; proper history taking, clinical examination, and proper radiological investigations (MRI, FISTA) when needed. They were divided into three groups according to treatment modality: group A where patient's general condition was unfit for surgical intervention, received oral medications (gabapentin or levetiracetam); group B included those patients unfit for surgical intervention and did not respond to oral therapy, received Botox injection; and group C underwent endoscopic assisted microvascular decompression. Follow-up period ranged from 6 to 24 months. Outcome of different treatment modalities were compared among different groups.

Results: Among group A patients, one patient showed excellent response to treatment (Gabapentin 1200 mg), three patients had good response, four patients had fair response, and three patients had poor response to treatment (one used levetiracetam, two used gabapentin). Overall success rate is $72.7 \%$. Among group B patients, four patients enjoyed excellent response. Another four patients had good response, while three patients had fair response. Only one patient had poor response. Overall success rate was $83.3 \%$. Among group C patients, five cases had excellent outcome and two cases had good outcome. Overall success rate is $100 \%$.

Conclusion: Endoscopic assisted microvascular decompression offers the best chance to permanent cure with low complication rate. New antiepileptics (levetiracetam, gabapentin) provide a safe therapy for patients refusing surgical intervention. Botox is an attractive local therapy with reversible complications but with non-sustainable effect. From our results, we conclude that endoscopic assisted microvascular decompression is superior to either BOTOX or antiepiletics for the permanent cure of hemifacial spasm.

Keywords: Hemifacia spasm, Endoscopic-microvascular decompression, Levetiracetam, Gabapentin, BOTOX

\footnotetext{
* Correspondence: drmoamenmorsy@gmail.com

'Neurosurgery, Faculty of Medicine, Kafr Elsheikh University, Kafr Elsheikh,

Egypt

Full list of author information is available at the end of the article
} 


\section{Introduction}

Hemifacial spasm (HFS) is a chronic movement disorder characterized by twitching of the muscles of facial expression which is innervated by the facial nerve. According to Auger et al., females affected as twice as males with the prevalence of 11 per 100,000. The most common etiology for hemifacial spasm is an ectatic or aberrant blood vessel that causes compression at facial nerve root entry zone leading to focal demyelination. The etiology of hemifacial spasm is categorized into two types: primary and secondary. Repetitive brief contractions started unilateral in the orbicularis oculi which lead to closure of the eye. These contractions are always associated with eyebrow elevation which is called the other Babinski sign. Then these contractions spread to other facial muscles. Magnetic resonance imaging (MRI) and electromyography (EMG) can be helpful in differentiating primary from secondary types of hemifacial spasms. Hemifacial spasm is a chronic condition where the best treatment modality has not been determined. Botulinum toxin remains the most popular treatment modality, but new oral pharmacotherapy and microsurgical decompression surgeries play an important role [1].

\section{Patients and methods}

This is a prospective study that was conducted on 30 consecutive patients suffering from hemifacial spasm in Alexandria Main University Hospital under protocol approved by the Research Ethics Committee of Faculty of Medicine. We excluded patients with myokymia focal undulating, muscle contraction), tardive dyskinesia, and other forms of facial or oro-mandibular dystonic movements. All patients signed an informed consent. MRI was done to all patients (including t2-weighted narrow slices (FIESTA or CISS type) before treatment to identify the presence of any neurovascular conflict at the area of the root entry zone of the facial nerve.

The patients were divided into three groups according to the management plan: group A included those patients with a poor general condition and are unfit for surgical maneuvers and those patients who received oral medications (gabapentin or levetiracetam). Dosage, any side effects, duration, and response to treatment were documented. Group B included those patients unfit for surgical intervention but did not respond to oral therapy and patients managed by local intramuscular Botox injection of the affected muscle. The response to BTX-A injection, number of units of the BTX-A, latency from the time of injection to the onset of effect, side effects, and the total duration of the effect were recorded. Group C underwent endoscopic assisted microvascular decompression. Total intravenous anesthesia was used without muscle relaxant to allow intraoperative facial nerve monitoring. The patients were placed in lateral position. A retromastoid craniectomy was performed; the dura was opened parallel to sinus edge, and arachnoid was opened sharply to release CSF to relax the cerebellum. Intermittent gentle cerebellar retraction was used when needed. Microvascular instrument under microscopic magnification were used to release any arachnoid bands and exploration of CPA, and $0^{\circ}$ and/or $30^{\circ}$ scope was used introduced to explore the root entry zone of the facial nerve. Offending vessel compressing facial nerve at the root entry zone was mobilized, and shredded Teflon was placed in between. Final endoscopic viewing of the root entry zone was done to ensure adequate decompression.

Neurophysiological monitoring of the facial nerve and brain stem-evoked potentials were used to add more safety to the operative procedure.

Outcome of treatment were compared among different groups according to the following scale; the outcome was classified into 5 grades, on the basis of the degree of HFS: (1) "excellent" if there was no residual spasm, (2) "good" if the HFS was more than 90\% resolved, (3) "fair" for spasm relief of $50 \%$ to $90 \%$, (4) "poor" if the HFS was less than 50\% resolved, and (5) "failure" for all remaining results. We considered poor and failure results as failure of therapy. Follow-up period ranged from 6 to 24 months.

Statistical analysis was carried out. Data were fed to the computer and analyzed using IBM SPSS software package version 20.0 (Armonk, NY: IBM Corp). Qualitative data were described using number and percent. The Kolmogorov-Smirnov test was used to verify the normality of the distribution. Quantitative data were described using range (minimum and maximum), mean, standard deviation, median, and interquartile range (IQR). Significance of the obtained results was judged at the $5 \%$ level. The used tests were (1) chi-square test, for categorical variables, to compare between different groups; (2) Monte Carlo correction, correction for chisquare when more than $20 \%$ of the cells have expected count less than 5; (3) Mann-Whitney test, for abnormally distributed quantitative variables, to compare between two studied groups.

\section{Results}

The mean of age at onset was 51.8 among all patients (range 40-65 years). The female-to-male ratio was 2.75: 1. The mean durations of the condition were 37.3 months in group A, 34.9 months in group B, and 46 months in group $C$, respectively. The left side was the most common side affected. The associated morbid conditions were hypertension and diabetes. Among group A, six patients received gabapentin in doses (800-1200 $\mathrm{mg})$, and five patients received levetiracetam in doses (1500-2000 mg). Two to three weeks lapsed to reach 
therapeutic response. One patient showed excellent response to treatment (Gabapentin $1200 \mathrm{mg}$ ), three patients had good response, four patients had fair response,, and three patients had poor response to treatment (one used levetiracetam and two used gabapentin). Overall success rate is $72.7 \%$. Five patients had dizziness that was temporary. Two patients suffered from somnolence, while one patient suffered from confusion that necessitated reduction of the dose (Gabapentin, Fig. 1).

Among group B patients, all patients received Botox injections that were tailored according the muscles affected. Total dose range was $20-50 \mathrm{U}$ with a mean of $36.7 \mathrm{U}$. There was delay in the onset of the effect ranging from 4 to 12 days with a mean of 7 days. The Botox effect lasted from 15 to 24 weeks (mean, 20.5 weeks). Four patients enjoyed excellent response. Another four patients had good response, while three patients had fair response. Only one patient had poor response. Overall success rate was $83.3 \%$. Two patients had ptosis that lasted less than month, one patient suffered from lid swelling, and one patient had mouth dropping which lasted two months to be resolved (Fig. 2).

Among group C patients, AICA was found compressing the nerve in four patients. PICA was the offending vessel in two patients and dolichoectatic vertebral artery in one patient. Five cases had excellent outcome, and two cases had good outcome. Overall success rate is $100 \%$. Only one case showed delay response to surgery (4 days) with an incidence of $14 \%$. We had one case with CSF leak that stopped by repeated lumbar puncture. Two cases showed temporary decrease in hearing that returned to baseline within one month (Fig. 3, Tables 1 and 2).

\section{Discussion}

Hemifacial spasm is a chronic condition affecting aged people with female predominance. Among our patients, mean of age was 51.8 years, where females are affected more than twice as males similar to what was reported in literature (mean age was 49.2 years, the ratio of females to males was 3.6:1). Hypertension and diabetes prevailed among our patients, similar observation noted by Chaudhry et al., who stated that hemifacial spasm and hypertension were coexistent in $40 \%$ of cases and hypertension can cause vessel ectasia which is the underlying etiology in most of the patients [1]

Although we believe that the best treatment option in cases suffering from hemifacial spasm is MVD, which may in certain cases be assisted by endoscopy, yet in patients where no definite vascular conflict identified in the MRI, or in those patients who were unfit for any surgical maneuver we had to seek other treatment modalities.

The current pharmacological management of hemifacial spasm included baclofen, carbamazepine, clonazepam, local doxorubicin, and other antiepileptic drugs (AEDs). Both baclofen and AEDs produced intolerable adverse effects, and new effective drugs are needed. Levetiracetam is an anticonvulsant drug with anti-kindling effect which is considered the pathogenesis of hemifacial spasm. There were few reports describing the efficacy of levetiracetam in the treatment of hemifacial spasm. We

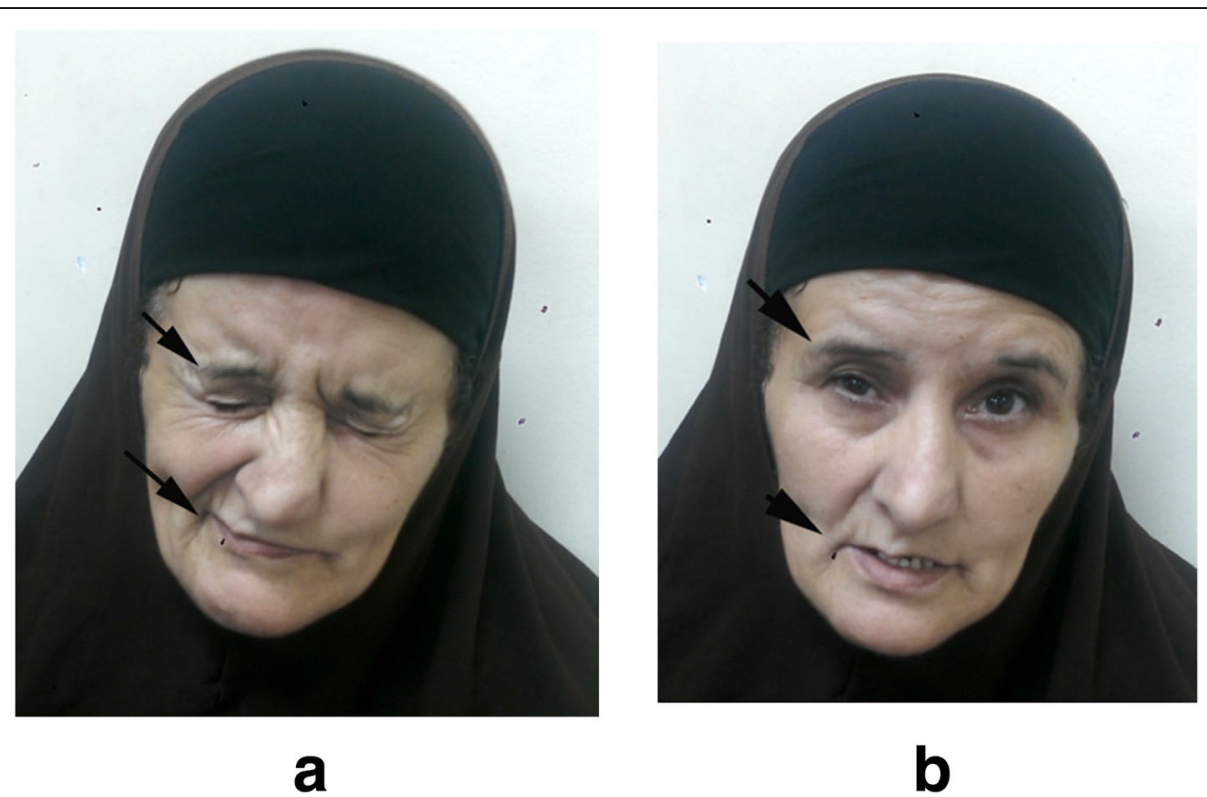

Fig. 1 A case of hemifacial spasm treated medically. a Pre-treatment status: right side hemifacial spasm involving upper and lower face, mouth deviation was observed. b Post treatment status: improvement in hemifacial spasm 

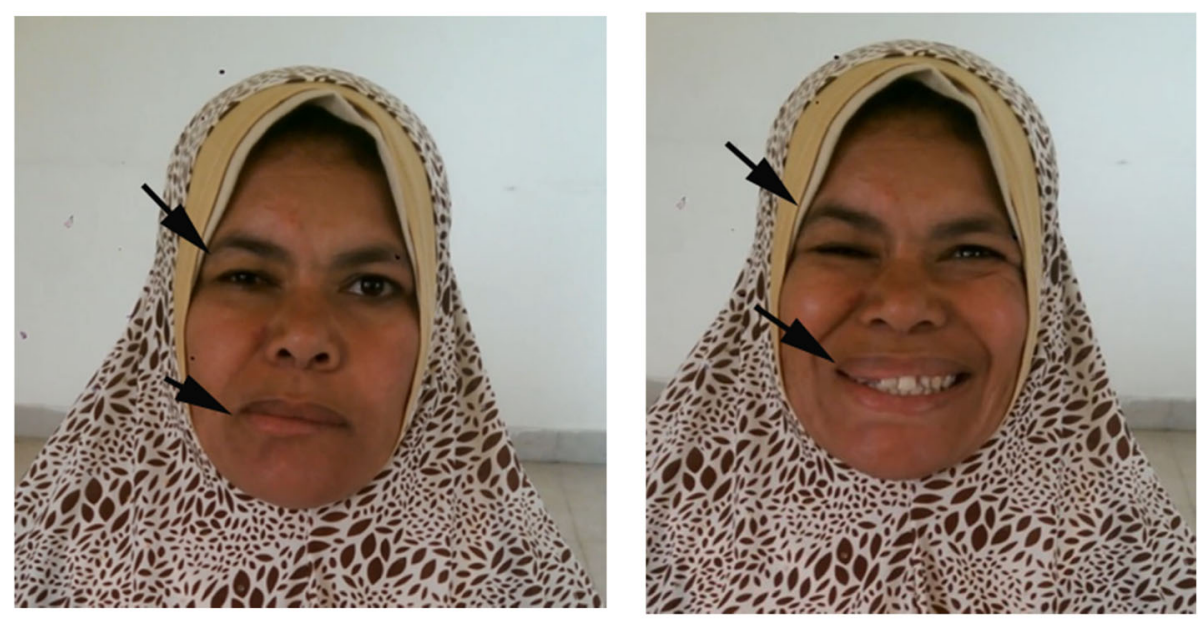

a
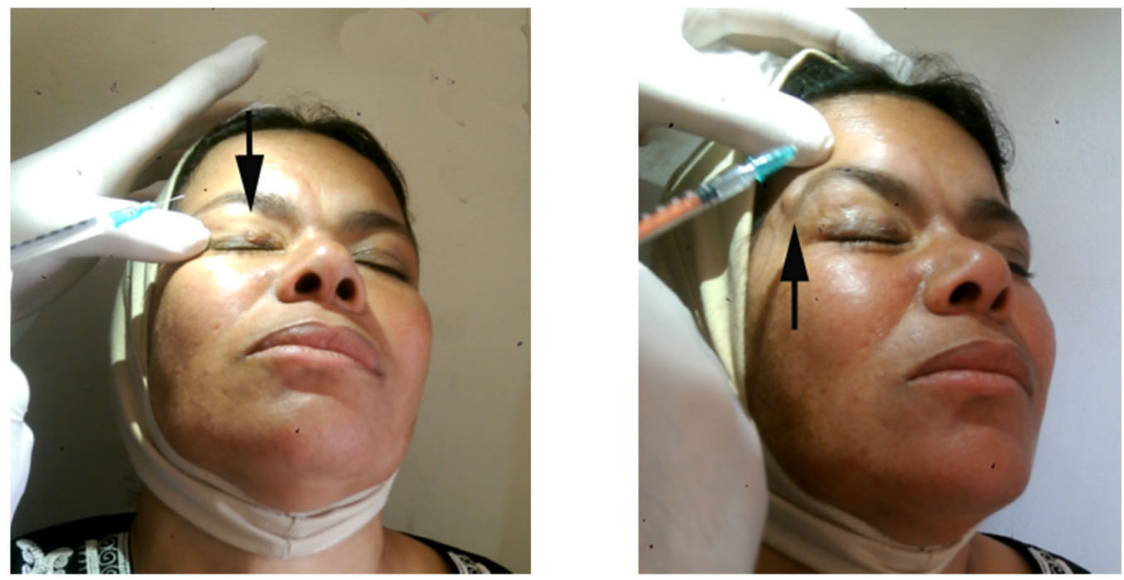

b

Fig. 2 A case of hemifacial spasm treated with Botox injection. a Pre-procedure status: spasm in orbicularis occuli is noted. b Botox injection procedure. c Early post procedure status: weakness in orbicularis occuli was noted. d During follow up: improvement of orbicularis occuli power

used a dose ranging from 1500 to $2000 \mathrm{mg}$ that was higher than the dose in literatures (500-1500 $\mathrm{mg}$ ) and yet showed non-increase in side effect because of the safety profile of the drug. All patients showed good compliance with maintained efficacy similar to Kurado et al., who showed a maintained response. One patient in our study showed poor response with levetiracetam that may be attributed to the compressive nature of the condition [2].

Gabapentin (GBP) is an antiepileptic drug with a safety profile and a mechanism of action involving GABAergic activities. It exerts its effect by reduction in either ephaptic transmission or hyperexcitability of the motor nucleus of the seventh nerve by increasing GABA levels. It showed efficacy in reducing hemifacial spasm in a dose ranging from 800 to $1200 \mathrm{mg}$ which was lower than the dose prescribed in other series (900-1600 mg). All side effects were temporary except for one patient who suffered from confusion that necessitated reduction of the dose. An open-label pilot study with this drug showed an overall success rate of $69.5 \%$ which was comparable to our results [3].

The mean of Botox dose was $36.7 \mathrm{U}$ that was similar to the mean reported by Sorgun et al. (34.5 $\mathrm{U}$ with range 19.5-85 U). Among our patients, there was a mean of 7 days of delay similar to what was found by Sorgun et al. An average of 8 days lapsed since the first improvement (range 1-40). According to Kollewe et al., Rudzinska, and Poonyathalang et al., the latency was between 2 and 14 days. In our study, Botox effect lasted from 15 to 24 weeks (mean 20.5 weeks) similar to what was found by Kollewe et al. and Poonyathalang et al., where the mean duration of improvement was 15.7 weeks (range 6.5- 


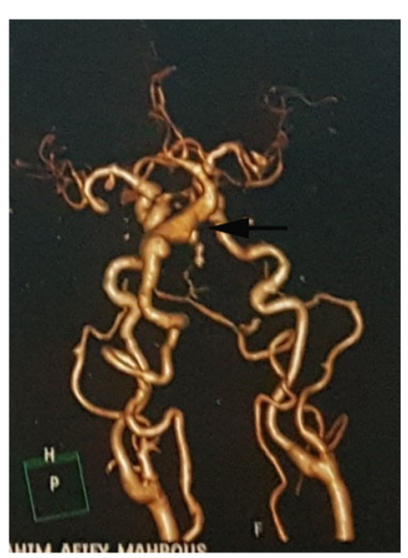

a

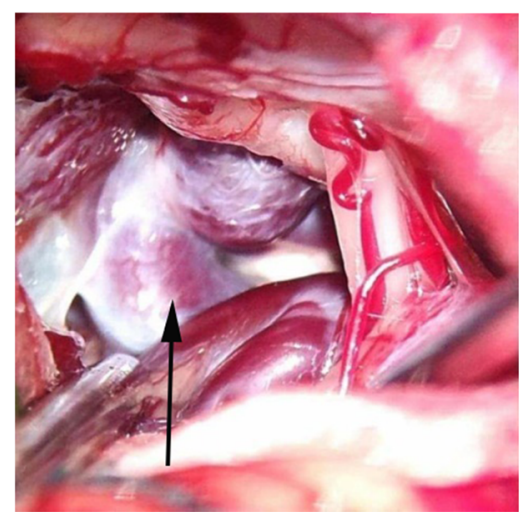

b

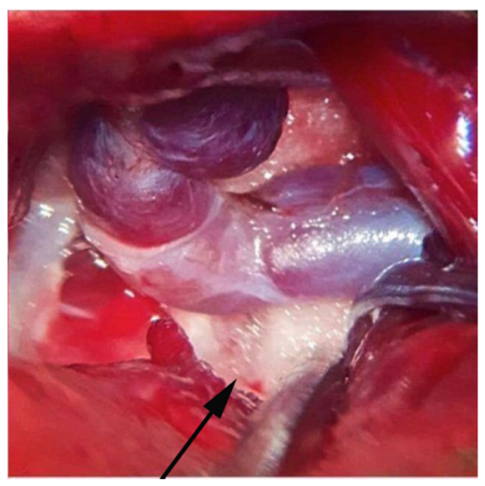

C

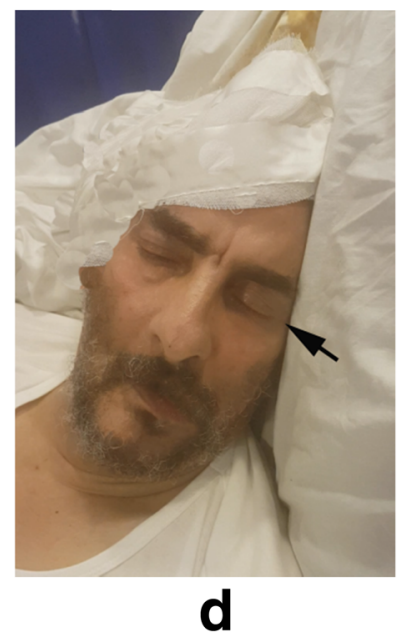

Fig. 3 A case of hemifacial spasm treated surgically with microvascular decompression. a MRA showing dolicoectatic vertebral artery. b Intraoperative view showing ectatic vessel compressing root entry zone via retrosigmoid approach. $\mathbf{c}$ Intraoperative view after mobilization of the vessel with Teflon placement to maintain new position. $\mathbf{d}$ Early postoperative view showing improvement in spasm

24.3 weeks). Overall success rate was $83.3 \%$ among our patients. Similar result was reported by Sorgun et al., where the degree of improvement was $73.7 \%$. According to literature, $86.7 \%$ of patients treated with botulinum toxin injections (range 73-96.9\%) reported an improvement [4-10].

Nearly one third of our patients suffered from side effect that was temporary (resolved within a 
Table 1 Distribution of age, gender, facial muscles affected, side, and previous treatments

\begin{tabular}{llll}
\hline & Group A & Group B & Group C \\
\hline No. of patients & 11 & 12 & 7 \\
Age range & $45-61$ & $40-65$ & $40-55$ \\
Gender & & & \\
$\quad$ Male & 4 & 3 & 1 \\
$\quad$ Female & 7 & 9 & 6 \\
Facial muscles affected & & & \\
$\quad$ Upper facial muscles & 3 & 2 & 0 \\
$\quad$ Upper and lower facial muscles & 6 & 7 & 7 \\
$\quad$ Upper, lower and platysma & 2 & 3 & 0 \\
Side & & & \\
Right & 3 & 4 & 2 \\
Left & 8 & 8 & 5 \\
Previous treatment & & & \\
$\quad$ Drugs & 9 & 10 & 7 \\
Botox & 3 & 2 & 0 \\
\hline
\end{tabular}

maximum of two months). According to literature, side effects were usually mild and transient and improved within a month. Ptosis was our most frequent side effect similar to what was reported by Sorgun et al. (range 2.5-72.2\%) followed by facial weakness (range 4.5-76.9\%). The side effect duration and degree were related to several factors like age. Price et al. found that orbital injections near the inner canthus were related to a higher incidence of ptosis. Defazio et al. found that the percentage of side effects was be related to dosage. Cakmur et al. reported higher success rates, longer durations of improvement, and fewer side effects with pretarsal injections $[4,9,11,12]$.

Among the surgical group, AICA was the main compressing vessel. Similarly, Li et al., Dannenbaum et al., Hyun et al., and Fukuda et al. found that AICA was the responsible vessels. Badr-El-Dine et al., Cheng et al., and Mooij et al. found that PICA was the main offending vessel [13-19].

We had one patient who showed delayed cure (14\%) for only 4 days. According to Sindou et al., delayed effect ranged from $5 \%$ to $50 \%$ in literature. Jo et al. who studied a delayed cure among surgically treated patients stated that not all of the patients are cured immediately

Table 2 Comparison between the three studied groups according to latency of effect, outcome, and side effect

\begin{tabular}{|c|c|c|c|c|c|c|c|c|}
\hline & \multicolumn{2}{|c|}{$\begin{array}{l}\text { Group A } \\
(n=11)\end{array}$} & \multicolumn{2}{|c|}{$\begin{array}{l}\text { Group B } \\
(n=12)\end{array}$} & \multicolumn{2}{|c|}{$\begin{array}{l}\text { Group C } \\
(n=7)\end{array}$} & \multirow[t]{2}{*}{ Test of Sig. } & \multirow[t]{2}{*}{$p$} \\
\hline & No. & $\%$ & No. & $\%$ & No. & $\%$ & & \\
\hline \multicolumn{9}{|l|}{ Latency } \\
\hline No delay & 0 & 0.0 & 0 & 0.0 & 6 & 85.7 & $x^{2}=19.259^{*}$ & $\mathrm{MC}_{p}<0.001^{*}$ \\
\hline Delay & 11 & 100.0 & 12 & 100.0 & 1 & 14.3 & & \\
\hline Duration of latency (mean) & \multicolumn{2}{|c|}{2.5 weeks } & \multicolumn{2}{|c|}{1 week } & \multicolumn{2}{|c|}{0.075 week } & & \\
\hline Min.-Max. & \multicolumn{2}{|c|}{$14.0-21.0$} & \multicolumn{2}{|c|}{$3.0-12.0$} & & & $U=0.000^{*}$ & $<0.001^{*}$ \\
\hline Mean \pm SD & \multicolumn{2}{|c|}{$17.18 \pm 3.66$} & \multicolumn{2}{|c|}{$7.0 \pm 2.59$} & \multicolumn{2}{|l|}{$4.0^{\#}$} & & \\
\hline Median & \multicolumn{2}{|l|}{14.0} & \multicolumn{2}{|l|}{7.0} & & & & \\
\hline IQR & \multicolumn{2}{|c|}{$14.0-21.0$} & \multicolumn{2}{|c|}{$5.0-8.75$} & & & & \\
\hline \multicolumn{9}{|l|}{ Outcome $e^{* *}$} \\
\hline Poor & 3 & 27.3 & 1 & 8.3 & 0 & 0.0 & $x^{2}=9.490$ & $\mathrm{MC}_{p}=0.118$ \\
\hline Fair & 4 & 36.4 & 2 & 16.7 & 0 & 0.0 & & \\
\hline Good & 3 & 27.3 & 5 & 41.7 & 2 & 28.6 & & \\
\hline Excellent & 1 & 9.1 & 4 & 33.3 & 5 & 71.4 & & \\
\hline Over all outcome & \multicolumn{2}{|c|}{$72.7 \%$} & \multicolumn{2}{|c|}{$91.6 \%$} & \multicolumn{2}{|c|}{$100 \%$} & & \\
\hline \multicolumn{9}{|l|}{ Side effect } \\
\hline Absent & 3 & 27.3 & 8 & 66.7 & 4 & 57.1 & $x^{2}=3.657$ & ${ }^{M} C_{p}=0.208$ \\
\hline Present & 8 & 72.7 & 4 & 33.3 & 3 & 42.9 & & \\
\hline
\end{tabular}

$x^{2}$ Chi square test, $M C$ Monte Carlo, U Mann-Whitney test

$p p$ value for comparing between the studied groups

*Statistically significant at $p \leq 0.05$

"Excluded from the comparison due to small number of case $(n=1)$

***oor = failure of therapy; excellent, good, and fair = success of therapy 
after surgery. Ishikawa et al. found a delay in cure in $50 \%$ of patients that last for a week in $25 \%$, one month in $50 \%$, and eight months in $90 \%$ of delayed cured patients [20-22].

All our patients enjoyed either excellent or good cure rate with no recurrence during follow up. Huh et al. found that the surgical outcome of MVD was excellent or good in $94.6 \%(n=1442)$. According to Miller et al., cure of spasm occur in $91.1 \%$ of the patients, delayed in $11.2 \%$, and recurrence rate was $2.4 \%$. Surgery was repeated in $1.2 \%$. Excellent result occurred in $84 \%$ with recurrence rate $1.5 \%$. Sindou et al. reviewed 5.935 patients and found that excellent results obtained in a range from $68 \%$ to $94.1 \%$, recurrence rate was low $1 \%$, incomplete resolution (more than or equal to $50 \%$ relief) ranged from $4.6 \%$ to $19 \%$ and failure (effect less than $50 \%$ ) from $3.6 \%$ to $15.5 \%$ [20, 23-25].

We had one case with CSF leak that required repeated lumbar puncture with antibiotic coverage. Two cases showed temporary decrease in hearing that returned to preoperative status within one month. According to Sindou et al., CSF leakage was reported as a frequent complication ranging from $2.5 \%$ to $10 \%$ which was presented as pseudomeningeocele, rhinorrhea, or CSF fistula with secondary meningitis. Huh et al. stated in his review of literature that $35.8 \%$ of patients suffered from complication where facial palsy, hearing deficit, and lower cranial nerve dysfunction were the most common ones. The mean time to recovery from transient hearing impairment was longer than that of facial palsy that could be explained by the fact that motor nerves (facial nerves) are less susceptible than the cochlear nerve to traction and/or ischemic trauma. The time to improve in hearing deficit was within 12 months that was longer than with our patients (within 1 month) that could be due to milder hearing affection with our patients. Sindou et at. reported that not all postoperative hearing dysfunctions are not from internal ear or cochlear nerve damages, some are related to middle ear alterations. Opening of large mastoid cells may generate an impression of otophonia. Middle ear effusion of fluid (blood or CSF in first postoperative days) through opened mastoid cells may alter auditory conduction [20, 23].

The study aims at highlighting that hemifacial spasm although being not so frequent in the neurosurgical practice, but those patients suffer a lot, and should be offered a treatment plan in spite of any co-morbid medical condition. We hereby illustrate our experience in dealing with such cases, according to their general condition and imaging. Microvascular decompression of the facial nerve is the treatment of choice whenever possible. Introducing an endoscope for better visualization of the root entry zone adds up to the effectiveness and precision of the procedure and thus offering our patient the best available treatment modality. Neurophysiological monitoring of the facial nerve and brain stem-evoked potentials were used to add more safety to the operative procedure.

\section{Conclusion}

Endoscopic-assisted microvascular decompression of the facial nerve offers the best opportunity to permanent cure with low complication rate. The use of endoscopy gives the surgeon the capability of adequate mobilization of the offending vessel to ensure decompression of the root entry zone. Levetiracetam and gabapentin are new antiepileptic drugs with anti-kindling effect and both show promising results in the control of hemifacial spasm with few side effects. Botox is an attractive local therapy with reversible self-limited complications most suitable for patients who refuse either surgery or medication. From our results, we conclude that surgical intervention is superior to either BOTOX or antiepiletics.

\section{Abbreviations}

AEDs: Antiepileptics; AICA: The anterior inferior cerebellar artery; BoNT-

B: Botulinum toxin B; BOTOX: Onabotulinumtoxin A; BTX-A: Botulinum toxin A; CISS: Constructive interference in steady state; CNs: Cranial nerves;

CPA: Cerebellopontine angle; CT: Computerized tomography;

CTA: Computed topography angiogram; DRIVE MRI: Driven equilibrium (drive) magnetic resonance imaging; EMG: Electromyogram; FISTA: Fast iterative shrinkage-thresholding algorithm; GABA: Gamma-aminobutyric acid; GBP: Gabapentin; HFS: Hemifacial spasm; MI: Myocardial infarction; MRI: Magnetic resonance imaging; MVD: Microvascular decompression; PICA: Posterior inferior cerebellar artery; TN: Trigeminal neuralgia; TOF: Time of flight; U: Unit; VA: Vertebral artery

\section{Acknowledgements}

Not applicable

\section{Authors' contributions}

I certify that all authors have made substantial contributions to the work reported in the manuscript (e.g., data collection, data analysis, or writing or editing assistance). All authors read and approved the final manuscript.

\section{Funding}

I certify that no funding has been received for the conduct of this study and/or preparation of this manuscript.

Availability of data and materials

Not applicable

\section{Ethics approval and consent to participate}

This study was conducted in Alexandria Main University Hospital under protocol approved by Research Ethics Committee of Faculty of Medicine. Written consent was obtained from all patients before any intervention with explanation of all benefits and complication of any intervention.

The Ethics Committee of the Faculty of Medicine, Alexandria University is the constitution and operated according to ICH GCP guidelines and applicable

local and institutional regulations and guidelines which govern EC operation. Place of Ethics Committee approval: Faculty of Medicine, Alexandria

University

IRB NO: 00007555

FWA NO: 00018699

Type of review: full board review

Subject of research: human adult males and females

Name, Email: drmoamenmorsy@gmail.com

Name of the department: Department of Neurosurgery

Prof. DR. Maha Ghanem 
Chairman of Ethics Committee

Address: Faculty of Medicine Aexandria University, 17 Champollion Street, El Messalah, Alexandria, Egypt

Email: alexmedethics@yahoo.com

\section{Consent for publication}

Consent to publish was obtained from any individual person's data in any form (including individual details, images, or videos).

\section{Competing interests}

The authors have no conflicts of interest to declare.

\section{Author details}

${ }^{1}$ Neurosurgery, Faculty of Medicine, Kafr Elsheikh University, Kafr Elsheikh, Egypt. ${ }^{2}$ Neurosurgery, Faculty of Medicine, Alexandria University, Alexandria Egypt.

Received: 29 October 2019 Accepted: 13 December 2019

Published online: 07 April 2020

\section{References}

1. Chaudhry N, Srivastava A, Joshi L. Hemifacial spasm: the past, present and future. J Neurol Sci. 2015;356:27-31.

2. Kuroda T, Saito Y, Fujita K, et al. On efficacy of levetiracetam in primary hemifacial spasm. J Clin Neurosci. 2016:34:213-5.

3. Daniele $O$, Caravaglios G, Marchini C, Mucchiut L, Capus P, Natalè E. Gabapentin in the treatment of hemifacial spasm. Acta Neurol Scand. 2001; 104:110-2

4. Sorgun $M H$, Yilmaz R, Akin YA, et al. Botulinum toxin injections for the treatment of hemifacial spasm over 16 years. J Clin Neurosci. 2015;22:1319-25.

5. Kollewe K, Mohammadi B, Dengler R, et al. Hemifacial spasm and reinnervation synkinesias: long-term treatment with either Botox or Dysport. J Neural Transm. 2010;117:759-63.

6. Rudzinska M, Wojcik M, Szczudlik A. Hemifacial spasm non-motor and motorrelated symptoms and their response to botulinum toxin therapy. J Neural Transm. 2010:117:765-72.

7. Hallett M, Albanese A, Dressler D, Segal KR, Simpson DM, Truong D, et al. Evidence-based review and assessment of botulinum neurotoxin for the treatment of movement disorders. Toxicon. 2013;67:94-114

8. Yaltho TC, Jankovic J. The many faces of hemifacial spasm: differential diagnosis of unilateral facial spasms. Mov Disord. 2011;26:1582-92.

9. Abbruzzese G, Berardelli A, Defazio G. Hemifacial spasm. Handb Clin Neurol. 2011;100:675-80

10. Batla A, Goyal C, Shukla G, Goyal V, Srivastava A, Behari M. Hemifacial spasm: clinical characteristics of 321 Indian patients. J Neurol. 2012;259:1561-5.

11. Rosenstengel C, Matthes M, Baldauf J, Fleck S, Schroeder H. Hemifacial spasm Conservative and surgical treatment options. Dtsch Arztebl Int. 2012; 109(41):667-73.

12. Gil Polo C, Rodríguez Sanz MF, Berrocal Izquierdo N, Castrillo Sanz A Gutiérrez Ríos R, Zamora García Ml, et al. Blepharospasm and hemifacial spasm: long-term treatment with botulinum toxin. Neurol. 2013;28:131-6.

13. Li Z, Gao J, Wang T, et al. Retrospective clinical analysis of 320 cases of microvascular decompression for hemifacial spasm. Med. 2018;97:34-41.

14. Dannenbaum $M$, Lega BC, Suki D, et al. Microvascular decompression for hemifacial spasm: long-term results from 114 operations performed without neurophysiological monitoring. J Neurosurg. 2008;109:410-5.

15. Hyun SJ, Kong DS, Park K. Microvascular decompression for treating hemifacial spasm: lessons learned from a prospective study of 1,174 operations. Neurosurg Rev. 2010;33:325-3.

16. Fukuda M, Oishi M, Hiraishi T, et al. Facial nerve motor-evoked potential monitoring during microvascular decompression for hemifacial spasm. J Neurol Neurosurg Psychiatry. 2010;81:519-23.

17. Badr-El-Dine M, El-Garem HF, Talaat AM, et al. Endoscopically assisted minimally invasive microvascular decompression of hemifacial spasm. Otol Neurotol. 2002:23:122-8.

18. Cheng WY, Chao SC, Shen CC. Endoscopic microvascular decompression of the hemifacial spasm. Surg Neurol. 2008:70:40-6.

19. Mooij JJA, Mustafa MK, van Weerden TW. Hemifacial spasm: intraoperative electromyographic monitoring as a guide for microvascular decompression. Neurosurg. 2001;49:1365-71.
20. Sindou M, Mercier P. Microvascular decompression for hemifacial spasm: outcome on spasm and complications. A review. Neurochirurgie. 2018;64(2): $106-16$.

21. Jo KW, Kong DS, Park K. Microvascular decompression for hemifacial spasm: long-term outcome and prognostic factors, with emphasis on delayed cure. Neurosurg Rev. 2013;36:297-302.

22. Zhong J, Xia L, Dou NN, Ying TT, Zhu J, Liu MX, et al. Delayed relief of hemifacial spasm after vascular decompression: can it be avoided? Acta Neurochir (Wien). 2015:157:93-8

23. Huh R, Han IB, Moon JY, et al. Microvascular decompression for hemifacial spasm: analyses of operative complications in 1582 consecutive patients. Surg Neurol. 2008;69:153-7.

24. Miller LE, Miller VM. Safety and effectiveness of microvascular decompression for treatment of hemifacial spasm: a systematic review. Brit Neurosurg. 2012;26:438-44.

25. Wu Y, Davidson AL, Pan T, Jankovic J. Asian over-representation among patients with hemifacial spasm compared to patients with cranial-cervical dystonia. J Neurol Sci. 2010;298(12):61-3.

\section{Publisher's Note}

Springer Nature remains neutral with regard to jurisdictional claims in published maps and institutional affiliations.

\section{Submit your manuscript to a SpringerOpen ${ }^{\circ}$ journal and benefit from:}

- Convenient online submission

- Rigorous peer review

- Open access: articles freely available online

- High visibility within the field

- Retaining the copyright to your article

Submit your next manuscript at $\boldsymbol{\nabla}$ springeropen.com 